\title{
Tonality and the Cultural
}

\author{
DANIEL LEECH-WILKINSON \\ King's College London
}

\begin{abstract}
The emphasis in this response to Mine Doğantan-Dack's "Tonality: The Shape of Affect" is on the cultural construction of tonality and the ways in which that may encourage Western musicians to understand tonality as a fundamental psychological process. An alternative hypothesis is proposed in which tonality assists in the effective musical modelling of hunting, offering a means to relive the experience in social groups.
\end{abstract}

Submitted 2013 May 15; accepted 2013 June 10.

KEYWORDS: tonality, acculturation, listening, cadence, hunting

TONALITY - in the broad sense of a use of pitch material that tends to favor one pitch-class over the rest, treating it as a recurring focus-has figured surprisingly little in the growing literature on musical universals.[1] While usually listed among these, there seems to have been little detailed enquiry into the features shared among tonal systems; and so the extent to which they are really fundamental to music perception remains to be reliably assessed. That allows hypotheses as to the evolutionary age of tonality to settle at many different depths according to the author's view of what tonality does in our experience of music and of life. Mine Doğantan-Dack's highly interesting proposal ranges widely through recent work on music's possible role in natural selection and in the modern brain, and does so consistently with other suggestions relating music to fundamental human traits (Mithen, 2005; Cross, 1999). In that sense it belongs within the continuing reaction against Pinker's (1997) more utilitarian view of music as nice but only superficially useful. For researchers who sense that music goes deeper within them than almost anything else, this new proposal - that music helps us to learn how to control ourselves (to put it crudely) is strikingly attractive. Especially interesting is the emphasis on cadencing and its organization of return but not departure. Any model for social behavior that tends to lead it towards contentment and resolution is in a good position to claim to offer selective advantage, especially once conflict becomes weaponized.

Tonality is a complex phenomenon, not just in its handling of pitches within musical practices but also in its engagement with musical cultures, particularly with sets of beliefs about its identity and role. Because tonality is so important in Western music theory there may have been a tendency to overrate its importance in all traditions; and a danger, too - precisely because it has been so extensively theorized — of missing the huge importance of the cultural in our ideas about tonality. We have come to treat it as an objective mechanism rather than as one among many possible ways of listening. We have to be constantly on our guard in this respect, especially in music science because of the strong tendency of empirical work to assume that it speaks for all.

Much of this Western bias towards tonality as a cognitively dominant principle probably depends on music notation. Seeing notes as objects rather than experiences encourages the identification of systematic processes in their patterning, and also the belief that what is in the score wholly specifies music's identity and content. And while that belief has gone out of academic fashion in recent decades, a notion of "the music itself", contained in the notes, continues to appear in writings and discussions of all sorts as if it were an obvious given. Music's uses and associations are, by comparison, trivial issues: for the Western theorist, music takes little worthwhile meaning other than from the functional relations between its notes. Beneath a belief in the central role of tonality lies a further notion that tonality itself functions according to rules derived from nature through acoustics, so that simply sounding a tonal chord, never mind a conventional chordal progression, satisfies a listener through its natural properties. Tonality quickly becomes an almost mystical notion, deeply bound up with our biological situation.

This is not to suggest that Doğantan-Dack requires these beliefs as a basis for her theory-far from it - but only that it is very easy for those of us educated in this tradition, and practising it over a lifetime of playing and listening, to experience tonality as powerful and even fundamental. And that in turn makes it easier to see its basic properties as deep-seated. But how much of that is "natural" and how much cultural? Wong, Roy, and Margulis (2009) found that participants judged music of another culture more tense than 
that of their own, and the fact that music can be used so effectively to maintain or even enhance divisions between groups (Bakagiannis \& Tarrant, 2006) reminds us that music's ability to regulate behavior depends to a substantial extent on familiarity.

Lullabies are especially interesting in this context, for the features identified by researchers as universals touch only lightly on tonality through a tendency for falling intervals to predominate (related to the descending curve of carer-infant vocalizations).[2] On the other hand, lullabies' universals include quite specific features of performance practice. From the perspective of Western music it is surprising, to say the least, that a performance practice should be as hard-wired as a set of relationships between notes. In other words, what is and is not fundamental about music may be far more varied and surprising than we imagine.

It may be worth mentioning, also, the increasing amount of empirical work on listeners' ability to follow tonal and formal processes in Western music (discussed in Leech-Wilkinson, 2012). Findings are tending to show that listeners do not know or care if a piece ends away from the tonic, so at best only very local tonal processes are noticed. In that light, it seems uncertain whether the experience of tonality could have helped in organizing longer and longer temporal experiences. Atonal scores also make emotional trajectories and journeys through intensification and relaxation, showing (at any rate for this listener) how powerfully that can be achieved without tonality. Changing textures, rhythms, densities, registers, timbres, and contours may well be able to do all that is required of a model of affect regulation.

Can we be confident, therefore, that tonality, even in the broadest sense of the term, is that important an ingredient in musical experience in most cultures? It figures importantly in a number of musical theories, certainly, but that does not guarantee that it is important in listening (save possibly for theorists). We would need to see research into that question, involving members of many and contrasting non-Western cultures, before we could tell whether the perceptual importance attributed to tonality is at all widespread. It may very well be, but we cannot be confident as yet.

Another important ingredient in Doğantan-Dack's argument is the experience of music as being like other kinds of experience, in other words the way in which music so readily seems like styles of movement or states of mind. This characteristic of music makes it seem deep-rooted because it is easily mappable. The more varied are things and experiences that music seems to be like, the deeper we imagine it must go within our brains. There is, of course, a wealth of research showing these kinds of mappings, and Cross (1999) has argued persuasively for the selective advantages this could have brought. The phenomenon of large numbers of people seeming to share deep experiences of music while disagreeing about it in detail is so everyday that it seems hardly to need testing. But how can we feel confident that music is promiscuously mappable other than through cultural exposure? Fritz et al. (2009) have recently found Western musical emotions somewhat recognizable by members of a very different culture, but only somewhat and only for the most basic emotions. Is that enough?

A particularly intriguing idea in Doğantan-Dack's article is that feeling responses to the dynamic shapes inherent in cadencing, rather than the physical properties of the world around us (experience of gravity, and so on), might lie beneath our recognition of attractors including points of tonal arrival. Given the way we use the word "attract" - which is surely ultimately a word describing human relationships - to describe effects of gravity, magnetism, electrical charge, and so on, I find this very appealing. But in music feeling and motion become linked in our bodies through practice: the link is not there from the very beginning. Beginners' playing is not emotional or affective: it is just noisy and repetitive. Musical performance - and is this true also of musical cognition? - becomes affecting and affective later on, after years of experience. It would be valuable to find out whether tonal closure has such emotional association for young people or whether it is something that grows over years. It seems quite possible that it grows gradually, and that as it does so it comes to feel natural (leading, incidentally, to a propensity to accept hypotheses like this one).

With these caveats in mind, let us propose an alternative hypothesis. Let us suppose, for the sake of argument, that our response to music that delineates an emotional trajectory (and by no means all worlds musics do this) depends much less on tonality than on music's similarity to the experience of that key survival skill for our human and long pre-humanoid ancestors, hunting. Hunting, like music, involves a physical-emotional trajectory of increasing activity, crisis, and relaxation, experienced through increasing heartbeat, intense thrill, decreasing heartbeat and (when successful) fulfillment; in emotional terms, anticipation, achievement, satisfaction. Cadencing then models homecoming ("the home key", we still say, a place of safety and rest). From a male perspective, one might add, music's power might seem more likely to arise from this modeling than from any other, which only goes to emphasize the huge extent to which analogies like this are gendered and cultured. Clearly music did not enable hunting; rather it could have enabled the reliving, and in a sense (and perhaps before semantic language) the retelling, in a safe and 
social environment, with benefits for sociability and group cohesion of the sort proposed by Cross, of the most dangerously exciting experience that life had to offer.

I do not offer this as a serious hypothesis, although perhaps it could be made into one. Rather, my point is that because music maps so promiscuously a great variety of hypotheses as to music's evolutionary advantages can be proposed. With as wide a range of references as we see here, ranging across recent work in many of the relevant disciplines and drawn together into an elegant argument, a highly attractive case can be (indeed, has been) made. Since there is no possibility of definitive evidence in such studies, there may be a case for developing as many competing hypotheses as possible as, in effect, the only route (since refutation by testing is rarely possible) to find out which survives as the fittest.

\section{NOTES}

[1] On musical universals useful recent studies include Higgins (2006), Morrison and Demorest (2009), and Laukka, Eerola, Thingujam, Yamasaki, and Beller (2013).

[2] There is further discussion of this in Leech-Wilkinson (2006). Lullaby research is well-summarized and discussed by McDermott and Hauser (2005).

\section{REFERENCES}

Bakagiannis, S., \& Tarrant, M. (2006). Can music bring people together? Effects of shared musical preference on intergroup bias in adolescence. Scandinavian Journal of Psychology, Vol. 47, No. 2, pp. $129-136$.

Cross, I. (1999). Is music the most important thing we ever did? Music, development and evolution. In: S. Won Yi (Ed.), Music, Mind and Science. Seoul National University Press, pp. 1-39.

Fritz, T., Jentschke, S., Gosselin, N., Sammler, D., Peretz, I., Turner, R., Friederici, A. D., \& Koelsch, S. (2009). Universal recognition of three basic emotions in music. Current Biology, Vol. 19, No. 7, pp. 573-576.

Higgins, K.M. (2006). The cognitive and appreciative import of musical universals. Revue internationale de philosophie, Vol. 4, No. 238, pp. 487-503. www.cairn.info/revue-internationale-de-philosophie-2006-4page-487.htm.

Laukka, P., Eerola, T., Thingujam, N. S., Yamasaki, T., \& Beller, G. (2013). Universal and culture-specific factors in the recognition and performance of musical affect expressions. Emotion. Advance online publication. doi: 10.1037/a0031388

Leech-Wilkinson, D. (2006). Portamento and musical meaning. Journal of Musicological Research, Vol. 25, Nos. 3-4, pp. 233-261.

Leech-Wilkinson, D. (2012). Compositions, scores, performances, meanings. Music Theory Online, Vol. 18, No. 1. http://www.mtosmt.org/issues/mto.12.18.1/mto.12.18.1.leech-wilkinson.php

McDermott, J., \& Hauser, M. (2005). The origins of music: innateness, uniqueness, and evolution. Music Perception, Vol. 23, No. 1, pp. 29-59.

Mithen, S. (2005). The Singing Neanderthals: The Origins of Music, Language, Mind and Body. London: Weidenfeld \& Nicholson.

Morrison, S.J., \& Demorest, S.M. (2009). Cultural constraints on music perception and cognition. Progress in Brain Research, Vol. 178, pp. 67-77.

Pinker, S. (1997). How the Mind Works. London: Allen Lane. 
Wong, P.C.M., Roy, A.K., \& Margulis, E.H. (2009). Bimusicalism: the implicit dual enculturation of cognitive and affective systems. Music Perception, Vol. 27, No. 2, pp. 81-88. 